\title{
Komunikasi Sosial Capital Sebagai Dakwah Kultural Pada Masyarakat Islam Di Pelosok Desa
}

\author{
Supriyo Wira \\ Universitas Gadjah Mada Yogyakarta \\ supriowira@gmail.com
}

\begin{abstract}
Indonesia needs to have social capital so that groups living in a society consisting of approximately 500 ethnic groups can unite. Every ethnicity has the potential to maintain its culture and territory. Moreover, Indonesia is a country where most of the population lives in rural areas and only a small part lives in urban areas. With the lack of economic development and education in the rural villages, the information flowing in the villages is not as fast and significant as in the cities. Even the da'i (preachers) have to fight harder to gain trust, so that they can provide precise and accurate religious information to the village community. This study discusses deeper on how Social Capital communication as a cultural da'wah can touch the community, especially in rural areas, to absorb religious information properly and correctly. This case study employs literature review method in collecting the data. The descriptive approach employed in this study also helps investigate the status of the existing factors and then looks at the relationship between one factor and another. Human resources or human capital is a very important and strategic capital in the life of a community organization. This is especially in terms of how a preacher as a communicator can convey his da'wah message to the village community, with a cultural and belief approach. Such way of communication is what makes the village communities easier to accept the da'wah activities since they are based on trust, mutual understanding and shared values. In addition, the communicators also convey all information about religion according to the existing culture and beliefs.
\end{abstract}

Keywords: Sosial Capital Communication, cultural da'wah.

\begin{abstract}
Abstrak
Bangsa Indonesia perlu memiliki modal sosial agar kelompok-kelompok yang hidup dalam masyarakat yang terdiri dari lebih kurang 500 kelompok etnik dapat bersatu padu. Setiap etnik berpotensi untuk mempertahankan kultur dan wilayah teritorialnya. Dan Indonesia adalah negara yang sebagian besar penduduknya tinggal di daerah pedesaan dan hanya sebagian kecil yang tinggal di perkotaan, Dengan kurang berkembangnya perekonomian dan pendidikan di desa membuat informasi yang mengalir di desa tidak secepat dan sesignifikan seperti di desa. bahkan pada da'i harus berjuang lebih sulit untuk mendapatkan kepercayaan, sehingga dapat memberikan informasi keagamaan secara tepat dan akurat pada masyarakat desa. penelitian ini akan membahas secara mendalam bagaimana komunikasi Sosial Capital sebagai dakwah kultural dapat menyentuh masyarakat khususnya di pedesaan
\end{abstract}


untuk menyerap informasi keagamaan dengan baik dan benar. Dengan metode deskriptif ini juga menyelidiki status dari faktor yang ada kemudian melihat hubungan antara satu faktor dengan faktor lainnya. Karenanya metode deskriptif juga dinamakan studi kasus (status study) maka penelitian ini juga sebagian besar menggunakan metode studi pustaka. sumber daya manusia atau human capital merupakan modal yang sangat penting dan strategis pada sebuah kehidupan organisasi masyarakat. Apalagi bagaimana seorang da'i sebagai komunikator dapat menyampaikan pesan dakwahnya kepada masyarakat desa, dengan pendekatan budaya dan kepercayaan. Yang membuat masyarakat desa dapat dengan mudah menerima aktivitas dakwah berdasarkan kepercayaan (trust) saling pengertian (Mutual understanding) dan nilai-nilai bersama (shared value) menjadikan komunikasi dakwah di dalam desa, lebih diterima. Karena komunikator menyampaikan segala informasi tentang keagamaan menyesuaikan dengan budaya dan kultur yang ada.

Kata Kunci: Komunikasi Sosial Capital, dakwah kultural.

\section{Pendahuluan}

Bangsa Indonesia perlu memiliki modal sosial agar kelompok-kelompok yang hidup dalam masyarakat yang terdiri dari lebih kurang 500 kelompok etnik dapat bersatu padu. Setiap etnik berpotensi untuk mempertahankan kultur dan wilayah teritorialnya. Bahkan dalam al-qur'an dijelaskan AI-Quran juga mengungkap betapa pentingnya Sosial Capital itu, seperti tersurat dalam Surah AIHujarat, ayat 13

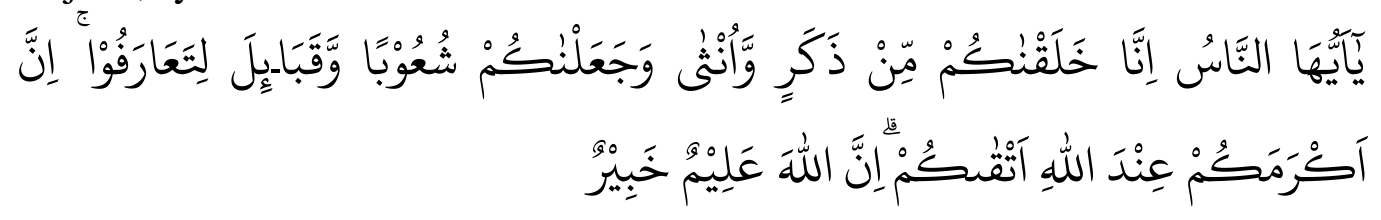

"Wahai manusia! Sungguh, Kami telah menciptakan kamu dari seorang laki-laki dan seorang perempuan, kemudian Kami jadikan kamu berbangsa-bangsa dan bersuku-suku agar kamu saling mengenal. Sesungguhnya yang paling mulia di antara kamu di sisi Allah ialah orang yang paling bertakwa. Sungguh, Allah Maha Mengetahui, Mahateliti"

Melihat hal tersebut, untuk mewujudkannya maka diperlukan para da'i yang mengorganisir dan mencetak para da'i serta harus dilengkapi dengan beberapa syarat atau faktor lain. Diantara faktor yang sangat diperlukan ialah kualitas para da'i dan keikhlasan dalam menyampaikan atau menyiarkan dakwah serta menggunakan metode yang sesuai dengan objek yang didakwahi. Dan bahwa Gambaran yang telah dikemukakan Lothorp Stoddard, aktivitas dakwah Islam yang dilakukan oleh Rasulullah saw, sahabat-sahabat dan para ulama sesudahnya, tetapi 
keberhasilan dakwah tersebut dikarenakan adanya proses penyampaian dakwah dengan menggunakan pendekatan sesuai dengan kondisi mad'u. ${ }^{1}$

Dan Indonesia adalah negara yang sebagian besar penduduknya tinggal di daerah pedesaan dan hanya sebagian kecil yang tinggal di perkotaan, ini mencirikan bahwa negara Indonesia merupakan negara agraris yaitu negara pertanian. Masyarakat yang mempunyai tingkat sosial ekonomi yang rendah cenderung memiliki tingkat pendidikan yang rendah pula. Masyarakat masih kurang memahami akan pentingnya pendidikan. Masyarakat masih beranggapan bahwa pendidikan bukan merupakan jaminan bisa hidup sejahtera, jauh dari kemiskinan. Dengan anggapan bahwa sekolah hanya membuang waktu dan biaya saja. Pendidikan dasar saja belum cukup untuk menunjang pembangunan yang sedang berlangsung, masih banyak masyarakat yang tidak berhasil menyelesaikan pendidikan dasar sampai dengan selesai. ${ }^{2}$ Dengan kurang berkembangnya perekonomian dan pendidikan di desa membuat informasi yang mengalir di desa tidak secepat dan sesignifikan seperti di desa. bahkan pada da'i harus berjuang lebih sulit untuk mendapatkan kepercayaan, sehingga dapat memberikan informasi keagamaan secara tepat dan akurat pada masyarakat desa. maka pada penelitian ini akan membahas secara mendalam bagaimana komunikasi Sosial Capital sebagai dakwah kultural dapat menyentuh masyarakat khususnya di pedesaan untuk menyerap informasi keagamaan dengan baik dan benar.

\section{Metode Penelitian}

Pendekatan penelitian ini menggunakan metode deskriptif untuk memperoleh data digunakan dengan cara observasi atau mencari referensi secara langsung dan juga data-data sekunder yang berkaitan dengan komunikasi Komunikasi Sosial Capital sebagai dakwah kultural pada masyarakat islam di pelosok desa. Penelitian ini juga disebut sebagai penelitian deskriptif, yang mempelajari masalah-masalah yang ada di dalam masyarakat, serta tata cara yang berlaku dalam masyarakat serta pada situasi tertentu, segala hal yang berhubungan dengan kegiatan, sikap dan pandangan juga proses yang berlangsung mempengaruhi suatu fenomena. Dengan metode deskriptif ini juga menyelidiki status dari faktor yang ada kemudian melihat hubungan antara satu faktor dengan faktor lainnya. Karenanya metode deskriptif juga dinamakan studi kasus (status study) maka penelitian ini juga sebagian besar menggunakan metode studi pustaka. ${ }^{3}$

\footnotetext{
1 Ariuddin Tike, "Model Dakwah Berbasis Masjid (Metode Dakwah di Desa Maradekayya Kecamatan Bajeng Kabupaten Gowa)," Jurnal Al-Khitabah 4, no. 1 (19 April 2018): 17, http://journal.uin-alauddin.ac.id/index.php/Al-Khitabah/article/view/4714.

2 Basrowi - dan Siti Juariyah, "Analisis Kondisi Sosial Ekonomi dan Tingkat Pendidikan Masyarakat Desa Srigading, Kecamatan Labuhan Maringgai, Kabupaten Lampung Timur," Jurnal Ekonomi dan Pendidikan 7, no. 1 (2010): 59, https://doi.org/10.21831/jep.v7i1.577.

${ }^{3}$ Tarjo, Metode Penelitian Sistem 3x Baca (Deepublish, 2019), 29.
} 
Penelitian ini merupakan penelitian kualitatif yang bersifat studi pustaka (library research) dengan menggunakan sumber data berupa buku-buku referensi dan artikel-artikel jurnal ilmiah. Pada penelitian ini rangkaian kegiatannya berkenanaan dengan pengumpulan data pustaka, membaca dan mencatat, lalu mengolah informasi yang sesuai dan diperlukan untuk menjawab rumusan masalah yang akan dipecahkan. Adapun prosedur yang dilakukan pada penelitian studi pusataka ini meliputi: 1) menggali ide umum tentang penelitian, 2) mencari informasi yang mendukungtopik penelitian, 3) mempertegas fokus penelitian dan mengorganisasi bahan yang sesuai, 4) Mencari dan menemukan sumber data berupa sumber pustaka utama yaitu buku dan artikel-artikel jurnal ilmiah, 5) melakukan reorganisasi bahan dan catatan simpulan yang didapat dari sumber data, 6) melakukan review atas informasi yang telah dianalisis dan sesuai untuk membahas dan menjawab rumusan masalah penelitian, 7) memperkaya sumber data untuk memperkuat analisis data dan 8) menyusun hasil penelitian. ${ }^{4}$

\section{Definisi Istilah}

1. Komunikasi

Pengertian Komunikasi adalah suatu aktivitas penyampaian informasi, berupa ide, pesan, dan gagasan, yang disampaikan oleh satu pihak ke pihak lainnya. karena aktivitas komunikasi dilakukan secara verbal atau lisan maka kegiatan komunikasi tersebut dapat memudahkan kedua belah pihak untuk saling mengerti. Maka definisi komunikasi, adalah interaksi antara dua orang atau lebih untuk menyampaikan suatu pesan atau informasi.

Komunikasi dapat diartikan secara umum yaitu bertujuan untuk memberikan pengetahuan kepada orang lain. Komunikasi yang baik adalah komunikasi yang dapat dimengerti dan diterima oleh orang lain. Selain dengan cara verbal, komunikasi juga bisa dilakukan dengan bahasa tubuh atau menggunakan gesture untuk tujuan tertentu. ${ }^{5}$

\section{Sosial Capital}

social capital merupakan keseluruhan sumber konsep aktual atau potensial, yang dihubungkan dengan kepemilikan dari suatu jaringan yang tahan lama atau lebih kurang hubungan timbal balik antar institusi yang dikenalnya. Dari berbagai kalangan penting, social capital sama dengan, sumber informasi. Gagasan, kesempatan bisnis, modal keuangan, power, dukungan emosional, goodwill,

\footnotetext{
${ }^{4}$ Lilik Tahmidaten dan Wawan Krismanto, "Permasalahan Budaya Membaca Di Indonesia (Studi Pustaka Tentang Problematika \& Solusinya)," Scholaria: Jurnal Pendidikan Dan Kebudayaan 10, no. 1 (24 Januari 2020): 25, https://doi.org/10.24246/j.js.2020.v10.i1.p22-33.

5 Deni Irawan dan Suriadi Suriadi, "Komunikasi Dakwah Kultural Di Era Millennial," Alhadharah: Jurnal Ilmu Dakwah 18, no. 2 (2 Maret 2020): 88, https://doi.org/10.18592/ alhadharah.v18i2.3383.
} 
kepercayaan dan kerjasama yang disediakan oleh individu dan jaringan sosial lainnya.

Maka Sosial Capital Menurut Coleman adalah kemampuan masyarakat untuk bekerja bersama-sama demi mencapai tujuan bersama di dalam berbagai kelompok dan organisasi. Modal sosial adalah bagian dari organisasi sosial seperti kepercayaan, norma dan jaringan yang dapat meningkatkan efisiensi masyarakat dengan memfasilitasi tindakan yang terkoordinasi. Modal sosial didefinisikan sebagai kapabilitas yang muncul dari kepercayaan umum di dalam sebuah masyarakat. Modal sosial diartikan sebagai serangkaian nilai (norma) informal yang dimiliki bersama dalam suatu kelompok yang memungkinkan terjalinnya kerjasama.

1stilah social capital pertama kali muncul pada tahun 1916 di saat ada diskusi tentang upaya membangun pusat pembelajaran masyarakat, Konsep Sosial Capital diangkat ke permukaan sebagai wacana ilmiah oleh James S. Coleman pada tahun 1990. Pembahasan tentang konsep sosial akhir-akhir ini semakin hangat setelah muncul tulisan Putnam pada tahun 1993 yang menggambarkan kualitas kehidupan masyarakat Amerika yang semakin menurun dalam hal kelekatan antar sesama warga. ${ }^{6}$

Teori Social Capital Ada tiga dimensi dari social capital yaitu ikatan (Bonds), jembatan (bridges), dan hubungan (lingkages), ikatan (Bonds) yang mengambarkan hubungan kekerabatan keluarga dekat, teman dekat, dan kolega profesional yang membantunya. Jembatan (bridges) menggambarkan hubungan yang agak jauh agar mengapainya. Sedangkan hubungan (lingkages) digambarkan sebagai dimensi vertikal sosial kapital dimana adanya pihak yang tidak termasuk dalam kekuasaan. Pada tingkat makro level sosial kapital pemerintah melekat pada rute of law, penegakan kontrak, dan bebas korupsi serta transparansi dalam mengambil keputusan, sistem administrasi yang efisien, sistem hukum yang dapat diandalkan. Singkatnya negara lebih mampu dan kredibel. ${ }^{7}$

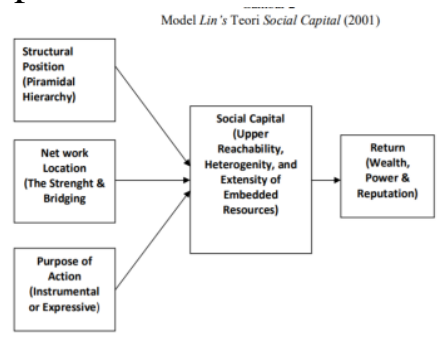

\footnotetext{
${ }^{6}$ Djamaludin Ancok, "Modal Sosial dan Kualitas Masyarakat," Psikologika: Jurnal Pemikiran dan Penelitian Psikologi 8, no. 15 (1 Januari 2003): 4, https://doi.org/10.20885/psikologika. vol8.iss15.art1.

7 Ghazali Syamni, "PROFIL SOCIAL CAPITAL SUATU KAJIAN LITERATUR," Jurnal Bisnis Dan Ekonomi 17, no. 2 (2010): 180, https://www.unisbank.ac.id/ojs/index.php/fe3/article/ view/335.
} 


\section{Dakwah kultural}

Pada pembahasan di bagian ini, akan dipaparkan mengenai wacana atau diskursus, yang dimulai dengan penjelasan mengenai dakwah secara definitif. Dalam bahasa Arab dakwah, yaitu دعوة- :Oئدعو- دعى yang berarti memanggil, menyeru dan mengundang. Kalau dilihat segi etimologinya terkesan kata dakwah dalam Al-Qur'an tidak selamanya digunakan untuk mengajak kepada kebaikan, akan tetapi terkadang pula digunakan untuk mengajak kepada keburukan atau kejahatan. Dakwah Islam kultural merupakan gerakan pemikiran keislaman yang berkembang di Indonesia dengan pendekatan ilmu sosial, seperti antropologi, ilmu budaya, sosiologi, dan sejarah. Sebagaimana pengertian kebudayaan tersebut sebagai sebuah hasil karya budi daya manusia. Ini merupakan pengertian yang sangat umum, namun jika dilihat dari bentuk kebudayaan yang dihasilkan yakni dalam dua bentuk, intelektual (pemikiran keiilsafatan, seni sastra), dan benda (benda-benda bersejarah). Istilah kultural berasal dari kata culture yang berarti kesopanan, kebudayaan, dan pemeliharaan.

Dakwah kultural gabungan antara teori dakwah yang sudah lama dikembangkan oleh para ahli dengan melihat kultur atau budaya masyarakat, Sedangkan dalam literatur antropologi terdapat tiga istilah yang boleh jadi semakna dengan kultural (kebudayaan), yaitu culture, civilization, kebudayaan. S. Takdir Alisyahbana mengatakan bahwa Term kultur berasal dari bahasa latin yaitu dari kata cultural (kata kerjanya colo, colere). Arti kultur adalah memelihara, mengerjakan, satu mengolah. Soemardjan dan Soelaiman Soemardi, mereka mendefinisikan kultur sebagai semua hasil karya, rasa dan cipta masyarakat, karya yang menghasilkan teknologi dan kebudayaan kebendaan (material culture) yang diperlukan manusia untuk menguasai alam. ${ }^{8}$

Dapat dikatakan bahwa dakwah Islam kultural dapat dimaknai sebagai sebuah dakwah Islamiyah yang dibangun berdasarkan perspektif kebudayaan untuk memahami Islam. Konsep dakwah memiliki makna yang kompleks. Aspek penting yang diuraikan dalam sub ini adalah terkait dengan model dakwah khususnya bagi kalangan da'i untuk mempertimbangkan pendekatan dakwah yang digunakan salah satunya adalah dengan menekankan aspek Social Capital. ${ }^{9}$

4. Dakwah

Sedangkan ditinjau dari segi terminologi, banyak sekali perbedaan pendapat tentang definisi dakwah di kalangan para ahli, antara lain: (1) Menurut A. Hasmy dalam bukunya Dustur Dakwah Menurut al-Qur'an, mendefinisikan dakwah yaitu: mengajak orang lain untuk meyakini dan mengamalkan akidah dan syariat Islam

\footnotetext{
${ }^{8}$ Irawan dan Suriadi, "Komunikasi Dakwah Kultural Di Era Millennial," 92.

9 Fahrurrozi, Model-model dakwah di era kontemporer: strategi merestorasi umat menuju moderasi dan deradikalisasi, Cetakan I (Mataram: Sanabil, 2017), 52.
} 
yang terlebih dahulu telah diyakini dan diamalkan oleh pendakwah itu sendiri. Lihat, A.Hasmy, Dustur Dakwah menurut al-Qur'an (2) Lihat Syekh Ali Mahfud. Dakwah Islam ad alah memotivasi manusia agar melakukan kebaikan menurut petunjuk, menyuruh mereka berbuat kebajikan dan melarang mereka berbuat kemungkaran, agar mereka mendapat kebahagian dunia dan akhirat. ${ }^{10}$

Tujuan dakwah adalah mengubah tingkah laku manusia, dari tingkah laku yang negatif ke tingkah laku yang positif. Sebagai seorang juru dakwah hendaklah dapat memahami kondisi yang menjadi objek dakwahnya. Ia harus mampu melihat persoalan-persoalan dengan lebih teliti dan mampu untuk memberikan solusi yang terbaik dalam setiap permasalahan. Oleh karena itu, persoalan dakwah tidak bisa terlepas dengan persoalan realita yang terjadi dalam masyarakat. ${ }^{11}$

\section{Pembahasan}

Proses dakwah Islamiah akan menghadapi permasalahan-permasalahan, sejalan dengan perkembangan peradaban manusia itu sendiri yang menyangkut politik, ekonomi, sosial, budaya dan ilmu pengetahuan yang selalu berubah. Sebab didalamnya terkait pula perubahan nilai terhadap cara pandang manusia terhadap perubahan-perubahan yang terjadi. Komunikasi Sosial Capital adalah proses menentukan cara dan upaya untuk menghadapi sasaran dakwah pada masyarakat desa dalam sitiuasi dan kondisi tertentu guna mencapai tujuan dakwah secara optimal.

Menurut Cohen dan Prusak menjelaskan bahwa Sosial Capital sebagai stok dan hubungan yang aktif antarmasyarakat. Setiap pola hubungan yang terjadi diikat oleh kepercayaan (trust) saling pengertian (mutual understanding), dan nilai-nilai bersama (shared value) yang mengikat anggota kelompok untuk membuat kemungkinan aksi bersama dapat dilakukan secara efisien dan efektif. Berdasarkan keterangan di atas, maka Sosial Capital sangat berkaitan dengan kegiatan suatu kelompok atau masyarakat untuk meningkatkan kesejahteraan sosial yang mengandung unsur: kepercayaan dan kejujuran (trust and honesty), norma dan nilai (norm and values), jaringan kerja (networking), kesetiakawanan sosial (solidarity), tanggungjawab (responsibility), kearifan lokal (local wisdom), keselarasan (harmony).

Maka komunikasi Sosial Capital dapat digunakan dengan cara sebagai berikut :

\footnotetext{
${ }^{10}$ Ibid., 51.

11 Abdul Najib, "POLA PENDEKATAN DAKWAH BERKELANJUTAN: PERSPEKTIF MODAL SOSIAL," KOMUNITAS 9, no. 2 (2017): 141, https://doi.org/10.20414/komunitas. v9i2.2193.
} 
1. Kepercayaan dan kejujuran (trust and honesty). Unsur penting dalam Sosial Capital adalah trust. Hilangnya minat masyarakat terhadap dakwah konvensional disebabkan karena hilangnya trust. Beda halnya dulu ketika masamasa Islam awal. Hal ini tidak dimiliki oleh para da'i masa kini, jika hal ini dibiarkan maka akan tetap normatif dan tidak adanya proses transformasi sosial yang merupakan hakikat dari dakwah itu sendiri.

2. Norma dan nilai (norm and values), bagi kalangan pelaku dakwah dalam mengemban strategi dakwahnya perlu memperhatikan aspek etis dari beberapa Norma-norma dan nilai yang dianut oleh masyarakat secara umum. Hal ini dapat memandu para da'i untuk berdakwah secara kontekstual dan situasional serta mampu membangun nilai-nilai indigenisitas bagi mad 'u.

3. Jaringan (networking), aspek penting dari modal sosial adalah membangun jejaring sosial bagi masyarakat. Sebagai contoh, dalam praktek dakwah bil hd] aktor dakwah mampu mengarahkan mad'u dalam membangun konektivitasnya.

4. Kesetiakawanan sosial (solidarity), nilai ini juga perlu dibangun dalam menciptakan suasana sustainablity yaitu selain kita mengajak kepada hal amar ma "ng"nah mungkar perlu juga menjunjung tinggi nilai-nilai persaudaraan (basic human right) yang bagian juga dari amar ma'ruf nahi mungkar.

5. Tanggungjawab (responsibility), nilai tanggung jawab merupakan sikap etis bagi kalangan da'i. Tanggung jawab tidak hanya sebatas pada saat proses penyampaian materi dakwah saja, namun perlu juga meninjau apakah masyarakat mengalami proses perubahan pada diri mereka serta mampu berbenah secara sosial maupun ekonomi.

6. Kearifan lokal (local wisdom), isu kearifan lokal ini merupakan salah satu bagian dari model manajemen dakwah yang menggunakan aspek nilai-nilai kemasyarakatan yang sesuai dengan pola mereka/self determination terminologi ini mampu memberikan sikap mandiri bagi masyarakat.

7. Keselarasan (harmony), prinsip dakwah adalah persamaan tanpa membedakan antara da'i dan mad'u dari aspek mobilitasnya, bila hal ini terjamin maka tidak akan terjadi gap/kesenjangan antara keduanya. ${ }^{12}$

Dakwah kultural adalah penyampaian ajaran Islam kepada yang ma'ruf, dengan memperhatikan potensi dan kecenderungan manusia sebagai makhluk budaya secara luas dalam rangka mewujudkan masyarakat Islam yang sebenarnya atau kegiatan dakwah dengan memanfaatkan adat, tradisi, seni dan budaya lokal yang terdapat dalam masyarakat sebagai proses menuju pada kehidupan Islami. Sehingga dapat disimpulkan bahwa komunikasi dakwah kultural adalah upaya dai (komunikator) untuk menyampaikan, pesan-pesan dakwah dalam bentuk gagasan

${ }^{12}$ Ancok, "Modal Sosial dan Kualitas Masyarakat," 55. 
atau ide, pendapat, saran, kepada mad'u (komunikan) dalam bingkai kemasan kultural (budaya) setempat.

Tuntutan dakwah berbasis modal sosial adalah; dakwah mesti diawali dengan kebutuhan masyarakat, dakwah mesti dilakukan secara terpadu, dakwah dilakukan secara partisipasi, dakwah dilakukan melalui sistematika pemecahan masalah, dakwah mesti dilakukan asas swadaya dan kerjasama masyarakat. Menurut Sayid Quthub bahwa dakwah dengan metode hikmah bil-hal akan terwujud apabila memperhatikan tiga faktor. Pertama, keadaan dan situasi orang-orang yang didakwahi. Kedua, ada atau ukuran materi dakwah yang disampaikan agar mereka tidak merasa keberatan dengan beban materi tersebut. Ketiga, metode penyampaian materi dakwah dengan membuat variasi sedemikian rupa yang sesuai dengan kondisi pada saat itu salah satunya adalah penekanan pada aspek modal sosial. ${ }^{13}$

Islam kultural adalah salah satu pendekatan yang berusaha meninjau kembali kaitan doktrinal yang formal antara Islam dan politik atau Islam dan negara. Hubungan antara Islam dan politik atau Islam dan negara termasuk wilayah pemikiran ijtihadiyah, yang tidak menjadi persoalan bagi umat Islam ketika sistem kekhalifahan masih bertahan di dunia Islam. Setelah hancur sistem kekhalifahan di Turki, dunia Islam di hadapkan pada sistem politik Barat. Terdapat dua dimensi besar dalam dakwah.

1. kebenaran yang merupakan pesan bagi nilai hidup dan kehidupan manusia yang seharusnya dimengerti, diterima, dan dijadikan dasar kehidupan oleh segenap umat manusia.

2. keterbukaan, yaitu bahwa proses penyerahterimaan pesan, antara dai dan mad'u hendaknya terjadi secara manusiawi, berdasar atas rasionalitas tertentu, dan tanpa paksaan. Itulah sebabnya, sejarah dakwah dikenal sebagai sejarah yang damai.

\section{Kesimpulan}

Berdasarkan beberapa uraian di atas dapat disimpulkan sumber daya manusia atau human capital merupakan modal yang sangat penting dan strategis pada sebuah kehidupan organisasi masyarakat. Apalagi bagaimana seorang da'i sebagai komunikator dapat menyampaikan pesan dakwahnya kepada masyarakat desa, dengan pendekatan budaya dan kepercayaan. Yang membuat masyarakat desa dapat dengan mudah menerima aktivitas dakwah berdasarkan kepercayaan (trust) saling pengertian (Mutual understanding) dan nilai-nilai bersama (shared value) menjadikan komunikasi dakwah di dalam desa, lebih diterima. Karena komunikator

${ }^{13}$ Najib, "POLA PENDEKATAN DAKWAH BERKELANJUTAN," 147. 
menyampaikan segala informasi tentang keagamaan menyesuaikan dengan budaya dan kultur yang ada.

Komunikasi Sosial Capital adalah proses menentukan cara dan upaya untuk menghadapi sasaran dakwah pada masyarakat desa dalam sitiuasi dan kondisi tertentu guna mencapai tujuan dakwah secara optimal. Sedangkan Dakwah kultural adalah penyampaian ajaran Islam kepada yang ma'ruf, dengan memperhatikan potensi dan kecenderungan manusia sebagai makhluk budaya secara luas dalam rangka mewujudkan masyarakat Islam yang sebenarnya atau kegiatan dakwah dengan memanfaatkan adat, tradisi, seni dan budaya lokal yang terdapat dalam masyarakat sebagai proses menuju pada kehidupan Islami. Sehingga dapat disimpulkan bahwa komunikasi dakwah kultural adalah upaya dai (komunikator) untuk menyampaikan, pesan-pesan dakwah dalam bentuk gagasan atau ide, pendapat, saran, kepada mad'u (komunikan) dalam bingkai kemasan kultural (budaya) setempat.

\section{Daftar Pustaka}

Ancok, Djamaludin. "Modal Sosial dan Kualitas Masyarakat." Psikologika: Jurnal Pemikiran dan Penelitian Psikologi 8, no. 15 (1 Januari 2003): 4-14. https://doi.org/10.20885/psikologika.vol8.iss15.art1.

Basrowi -, dan Siti Juariyah. "Analisis Kondisi Sosial Ekonomi dan Tingkat Pendidikan Masyarakat Desa Srigading, Kecamatan Labuhan Maringgai, Kabupaten Lampung Timur." Jurnal Ekonomi dan Pendidikan 7, no. 1 (2010). https://doi.org/10.21831/jep.v7i1.577.

Fahrurrozi. Model-model dakwah di era kontemporer: strategi merestorasi umat menuju moderasi dan deradikalisasi. Cetakan I. Mataram: Sanabil, 2017.

Irawan, Deni, dan Suriadi Suriadi. "Komunikasi Dakwah Kultural Di Era Millennial." Alhadharah: Jurnal Ilmu Dakwah 18, no. 2 (2 Maret 2020). https://doi.org/10.18592/alhadharah.v18i2.3383.

Najib, Abdul. "POLA PENDEKATAN DAKWAH BERKELANJUTAN: PERSPEKTIF MODAL SOSIAL." KOMUNITAS 9, no. 2 (2017): 140-48. https://doi.org/10.20414/komunitas.v9i2.2193.

Syamni, Ghazali. "PROFIL SOCIAL CAPITAL SUATU KAJIAN LITERATUR." Jurnal Bisnis Dan Ekonomi 17, no. 2 (2010). https://www.unisbank. ac.id/ojs/index.php/fe3/article/view/335.

Tahmidaten, Lilik, dan Wawan Krismanto. "Permasalahan Budaya Membaca Di Indonesia (Studi Pustaka Tentang Problematika \& Solusinya)." Scholaria: Jurnal Pendidikan Dan Kebudayaan 10, no. 1 (24 Januari 2020): 22-33. https://doi.org/10.24246/j.js.2020.v10.i1.p22-33.

Tarjo. Metode Penelitian Sistem 3x Baca. Deepublish, 2019.

Tike, Ariuddin. "Model Dakwah Berbasis Masjid (Metode Dakwah di Desa Maradekayya Kecamatan Bajeng Kabupaten Gowa)." Jurnal Al-Khitabah 4, no. 1 (19 April 2018). http://journal.uin-alauddin.ac.id/index.php/AlKhitabah/article/view/4714. 